\title{
Doubled Haploids in Eggplant
}

\author{
Ricardo Mir $^{\dagger}{ }^{+}$Antonio Calabuig-Serna ${ }^{+}($ib and Jose M. Seguí-Simarro * (D) \\ Cell Biology Group—COMAV Institute, Universitat Politècnica de València, 46011 Valencia, Spain; \\ rimimo@upv.es (R.M.); ancaser3@upv.es (A.C.-S.) \\ * Correspondence: seguisim@btc.upv.es; Tel.: +34-96-387-9047 \\ + These authors contributed equally to this work.
}

Citation: Mir, R.; Calabuig-Serna, A.; Seguí-Simarro, J.M. Doubled Haploids in Eggplant. Biology 2021, 10, 685. https://doi.org/10.3390/ biology10070685

Academic Editors: Pierre Devaux and Pierre Sourdille

Received: 22 June 2021

Accepted: 15 July 2021

Published: 20 July 2021

Publisher's Note: MDPI stays neutral with regard to jurisdictional claims in published maps and institutional affiliations.

Copyright: (c) 2021 by the authors. Licensee MDPI, Basel, Switzerland. This article is an open access article distributed under the terms and conditions of the Creative Commons Attribution (CC BY) license (https:// creativecommons.org/licenses/by/ $4.0 /)$.
Simple Summary: This review compiles the most relevant advances made in the production of doubled haploid plants in eggplant, the application of doubled haploid lines in breeding programs, and the future perspectives for the development of alternative technologies for doubled haploid generation in this species.

Abstract: Eggplant is a solanaceous crop cultivated worldwide for its edible fruit. Eggplant breeding programs are mainly aimed to the generation of F1 hybrids by crossing two highly homozygous, pure lines, which are traditionally obtained upon several self crossing generations, which is an expensive and time consuming process. Alternatively, fully homozygous, doubled haploid (DH) individuals can be induced from haploid cells of the germ line in a single generation. Several attempts have been made to develop protocols to produce eggplant DHs principally using anther culture and isolated microspore culture. Eggplant could be considered a moderately recalcitrant species in terms of ability for DH production. Anther culture stands nowadays as the most valuable technology to obtain eggplant DHs. However, the theoretical possibility of having plants regenerated from somatic tissues of the anther walls cannot be ruled out. For this reason, the use of isolated microspores is recommended when possible. This approach still has room for improvement, but it is largely genotype-dependent. In this review, we compile the most relevant advances made in DH production in eggplant, their application to breeding programs, and the future perspectives for the development of other, less genotype-dependent, $\mathrm{DH}$ technologies.

Keywords: androgenesis; anther culture; aubergine; haploidy; microspore culture; Solanum melongena

\section{Introduction}

Eggplant (Solanum melongena L.), also known as brinjal, aubergine, or Guinea squash, is a widely cultivated species for its edible fruits. In a broader sense, eggplant refers not only to S. melongena, but also to two other related African species, scarlet (S. aethiopicum L.), which is widely cultivated in Africa, and gboma (S. macrocarpon L.), a local species [1]. In this review, we will use "eggplant" to refer to $S$. melongena. Eggplant is one of the more than 3000 species belonging to the Solanaceae family. Several Asian regions such as India, different regions of China, or south-east Asian countries, have been proposed as the original domestication areas for this crop [2]. Among Solanaceae, eggplant is the third most cultivated species, after tomato and potato [3,4]. Indeed, eggplant cultivation currently covers 1.8 million hectares in the world, where nearly 55 million tons were produced in 2019 [4], with China and India being the main producers by far, followed by Egypt, Turkey, and Iran. Eggplant in the Mediterranean countries, as in Asia, is one of the top five most important vegetable crops [3]. Due to its economic importance, eggplant has been the focus of breeding programs. This has resulted in the generation of new varieties and hybrids, which entail a continuous rise in its production [5], which has doubled compared to twenty years ago with just a slight increase in cultivation area [4]. 
Hybrid seed production is based on the previous generation of pure, highly homozygous lines to be used as parentals. Pure lines have traditionally been obtained through several (6-10) self-crossing generations [6]. Eggplant is an autogamous species with large flowers that is easy to manipulate. Thus, it is technically feasible to obtain pure lines through conventional selfing and selection techniques. However, the time and costs required to generate new pure lines to test new F1 combinations are generally elevated [7,8]. Alternatively, the generation of homozygous, doubled haploid (DH) lines in a single generation can dramatically speed up this process, thereby becoming a convenient alternative to conventional approaches $[9,10]$. Currently, protocols for $\mathrm{DH}$ production have been described for almost 400 species [11] through the application of different in vivo and in vitro techniques such as pollination with irradiated pollen, interspecific and intraspecific crosses, crossing with natural or artificially produced haploid inducer lines, ovary or ovule in vitro culture, and isolated anther or microspore in vitro culture.

Anther and microspore culture are techniques used to induce embryogenesis in microspores, which are not naturally determined for this. It is therefore an experimental pathway that induces the development of microspore-derived embryos from haploid microspores under certain in vitro culture conditions. Since the first report of this phenomenon in Datura innoxia [12], protocols for many other species, including eggplant, have been reported [11]. Further genome duplication, artificially induced or not, results in the generation of fully homozygous DH individuals in a single generation [13]. The ability of microspores to develop as embryos, the so-called embryogenic response, is highly dependent on the genotype. Within the Solanaceae family, some tobacco lines show a very high embryogenic response, whereas tomato microspores are considered extremely recalcitrant to the induction of embryogenesis [8,13,14]. Despite this, although eggplant microspores are in general able to be induced to embryogenesis and generate haploid or DH embryos, they are still far from the efficiency of tobacco or other model species like Brassica napus in terms of embryogenic response.

In short, the generation of eggplant F1 hybrid varieties by crossing pure lines has favored the increment of eggplant productivity, as well as the improvement of other interesting agronomic traits. DH technology has the potential for accelerating the process of producing new parental pure lines in many different species, with eggplant considered a species moderately recalcitrant to the use of these techniques. Therefore, the optimization of $\mathrm{DH}$ protocols for this species is of general interest. Many different attempts have been made to develop new protocols or to improve the existing methods to produce DHs in this crop. To the best of our knowledge, all of them have explored microspore embryogenesis, either through anther culture or isolated microspore culture. A comparison of the main features of these two techniques is summarized in Table 1. In this review, we compile the main efforts made to generate eggplant $\mathrm{DHs}$, the methods used to produce them and their use in breeding programs (summarized in Table 2). Finally, we discuss the future possibilities of DH technology in this species.

Table 1. Comparison of anther and isolated microspore in vitro culture in eggplant.

\begin{tabular}{ccc}
\hline & Anther Culture & Microspore Culture \\
\hline Technical complexity & Lower & Higher \\
Applicability & Higher & Lower \\
Control of medium composition & Lower & Higher \\
Efficiency & Lower & Higher \\
Speed & Slower & Faster \\
Need for checking haploid origin & Yes & No \\
Microsposible & Not possible & Microspore-derived calli \\
Output & Microspore-derived embryos & \\
\hline
\end{tabular}


Table 2. Chronological advances in the protocol for eggplant DH production through anther and isolated microspore culture. a: anther culture, $\mathrm{m}$ : microspore culture.

\begin{tabular}{|c|c|c|}
\hline Technique & Year & Advance \\
\hline a & 1975 [15] & First report on eggplant anther culture. \\
\hline a & $1978[16]$ & First eggplant DH plantlets. \\
\hline$a, m$ & 1979 [17] & Combination of eggplant anther culture and microspore isolation. \\
\hline a & $1982[18]$ & First reproducible eggplant anther culture protocol. \\
\hline $\mathrm{m}$ & 1996 [19] & First report of eggplant microspore culture. \\
\hline a & $2006[20]$ & Effect of maltose in the embryogenic response. \\
\hline a & $2008[21]$ & Effect of cold stress preculture in the embryogenic response. \\
\hline $\mathrm{m}$ & $2011[22]$ & Colchicine-based genome doubling protocol. \\
\hline a & $2012[23]$ & Effect of stage for anther excision and heterostyly. \\
\hline $\mathrm{m}$ & $2012[24]$ & $\begin{array}{l}\text { Improved protocol for microspore-derived callus production by } \\
\text { starvation and heat stress. }\end{array}$ \\
\hline a & $2013[25]$ & Study of the effect of PAA and Gamborg (B5) salts. \\
\hline $\mathrm{m}$ & 2014 [26] & $\begin{array}{l}\text { Increased efficiency of microspore culture through modifications } \\
\text { of the culture medium. }\end{array}$ \\
\hline $\mathrm{m}$ & 2015 [27] & Optimization of plant regeneration from microspore-derived calli. \\
\hline a & $2017[28]$ & $\begin{array}{l}\text { Protocol improvement by replacement of kinetin by } \\
\text { zeatin riboside. }\end{array}$ \\
\hline a & 2017 [29] & Interaction between genotype and growth regulators. \\
\hline $\mathrm{m}$ & $2017[30]$ & Development of a DH line with high embryogenic response. \\
\hline $\mathrm{m}$ & $2017[31]$ & Role of calcium in microspore embryogenesis. \\
\hline $\mathrm{m}$ & 2019 [32] & $\begin{array}{l}\text { Role of the cell wall in the embryogenic response of different } \\
\text { species, including eggplant. }\end{array}$ \\
\hline $\mathrm{m}$ & $2020[33]$ & $\begin{array}{l}\text { Procedure for the identification of the microspore/pollen } \\
\text { responsive stages. }\end{array}$ \\
\hline a & $2020[34]$ & $\begin{array}{l}\text { Effect of maltose, silver nitrate and activated charcoal in the } \\
\text { embryogenic response. Establishment of a protocol for anther } \\
\text { culture in liquid medium. }\end{array}$ \\
\hline $\mathrm{m}$ & $2020[35]$ & $\begin{array}{l}\text { Effect of light intensity over donor plants and in vitro microspore } \\
\text { density in the embryogenic response. }\end{array}$ \\
\hline
\end{tabular}

\section{Anther Culture in Eggplant}

Anther culture is the simplest technical method to induce microspore embryogenesis. The first report on the development of eggplant DHs by anther culture was published in 1973 [15]. This report described how anthers cultured in Nitsch's medium supplemented with different concentrations of indole acetic acid (IAA) and kinetin developed DH plants from pollen-derived haploid calli and hypothesized that the change in the chromosome number was due to the spontaneous duplication of haploid cells during the early stages of callus proliferation. In 1978, the first haploid plantlets were obtained [16] and in 1979, the development of eggplant plantlets from microspore-derived calli through a combination of anther culture and microspore isolation was described [17]. It involved a pretreatment of the microspore-bearing anthers for four days and the posterior isolation of dividing microspores that, upon transference to Murashige and Skoog (MS) liquid medium supplemented with $2 \mathrm{mg} / \mathrm{L} \mathrm{1,4-D} \mathrm{and} 1 \mathrm{mg} / \mathrm{L}$ kinetin, proliferated into calli from which plantlets were regenerated.

The first reproducible protocol was described by Dumas de Vaulx and Chambonnet in 1982 [18]. Since then, it has been the most widely used technique (Figure 1). Briefly, it consists of the excision of flower buds at the right stage of development (Figure 1A) and, once in the laboratory, the extraction and surface-sterilization of anthers (Figure 1B), and their culture for 8 days at $35^{\circ} \mathrm{C}$ in darkness in a semisolid induction medium supplemented with $0.01 \mathrm{mg} / \mathrm{L}$ kinetin and $0.01 \mathrm{mg} / \mathrm{L} 2,4-\mathrm{D}$ (Figure 1C). Then, anthers are transferred to $25^{\circ} \mathrm{C}$ with a $12 / 12 \mathrm{~h}$ day/night photoperiod for four more days, and then subcultured in a regeneration media supplemented with $0.1 \mathrm{mg} / \mathrm{L}$ kinetin and kept at $25^{\circ} \mathrm{C}$ with a $12 / 12 \mathrm{~h}$ day/light photoperiod continuously. During the process, the anthers swell and necrose, while microspores proliferate within the pollen sac. Approximately two months later, 
microspore-derived embryos emerge from the anthers (Figure 1D). Then, they are removed from the anther and cultured until germination to produce a new microspore-derived in vitro plantlet (Figure 1E).

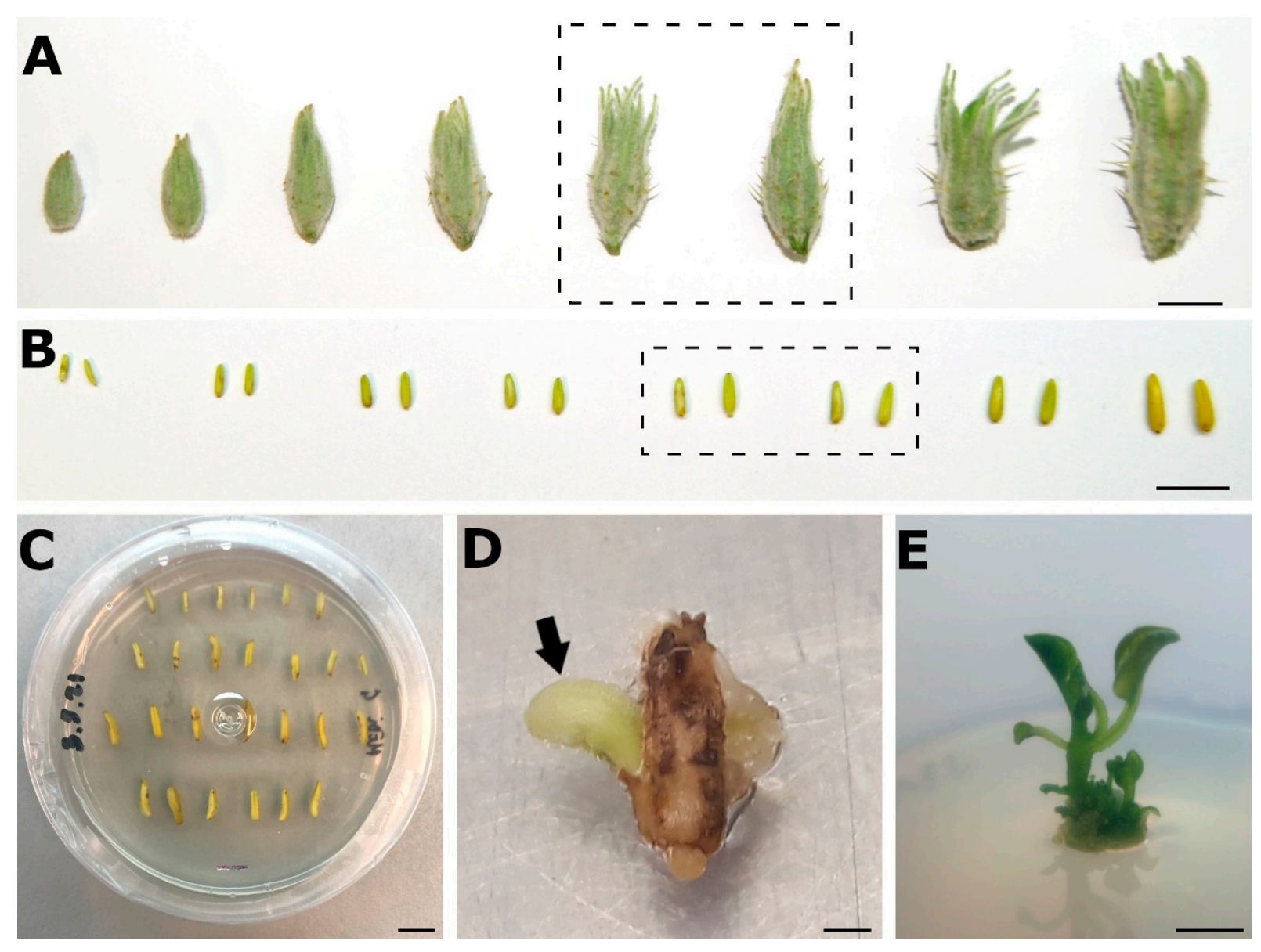

Figure 1. Anther culture in eggplant. (A). Range of developing eggplant floral buds. Developmental stages suitable for anther culture are boxed. (B). Range of eggplant anthers contained in the developing anthers shown in A. Anther sizes suitable for anther culture are boxed. (C). Anthers cultured in vitro on induction medium. (D). Microspore-derived embryo (arrow) emerging from a two month-old necrosing anther. (E). Eggplant plantlet produced in vitro from a germinated microspore-derived embryo. Bars: A-C, E: $1 \mathrm{~cm}$; D: $1 \mathrm{~mm}$.

There are several factors affecting the embryogenic response of cultured anthers. The most important is the genotype. Different studies point to the notion that the ability of microspores to undergo embryogenesis is an inheritable and therefore genetically regulated trait, as will be discussed below in a separate section. The gene or genes controlling this trait, however, are still awaiting discovery. The second relevant parameter that determines a successful induction of microspore embryogenesis is the stage of the microspores used for in vitro culture, either through anther culture or through microspore culture. It is widely acknowledged that the best stage to induce embryogenesis revolves around the first pollen mitosis $[13,33,36]$. This means that, in general, mature, vacuolated microspores and young, just divided pollen grains are the stages where embryogenesis can be induced more efficiently. However, in the literature there are reports that suggest other stages slightly different from these. In some cases, the discrepancies may come from the difficulty of correlating anther sizes and microspore/pollen developmental stages. Sometimes, the difference in length between an anther with microspores at a given stage and an anther with microspores at the immediately later stage is as small as a tenth of a millimeter, which makes it very difficult to precisely pin it down. Besides, all microspores in an anther are not usually at the same stage. Instead, different stages coexist within the same anther [23]. 
Sometimes, the percentages of adjacent stages are very similar, which makes it difficult to draw clear and widely applicable conclusions. Eggplant is a particular example of a species where discrepancies in the suitable stage of microspores/pollen have also been published. In addition to the factors mentioned above, the thickness of the anther wall must also be taken into account when performing anther culture, as it influences the velocity at which media components reach microspores inside the locules [23]. It was proposed that, for anther culture, anthers should be excised when microspores are younger in order to allow time to let microspores progress until the suitable developmental stage while the growth factors of the culture medium diffuse through the thick anther walls and reach the anther locule. If anthers are excised when microspores are at the suitable stage, they will be too mature and therefore unresponsive by the time growth factors reach the anther locule.

The third main factor that influences the embryogenic response is the in vitro culture conditions, including the stress used to induce the developmental switch, and the composition of the culture medium. The Dumas de Vaulx and Chambonnet method is at present the basis for most of the anther culture protocols available in eggplant and, as to the stress used, very little has changed. A heat shock stress of $35^{\circ} \mathrm{C}$ during several days is still the most used inductive treatment. However, different modifications have been proposed to adapt this method to improve its efficiency in specific eggplant varieties $[37,38]$. For example, the use of maltose was reported to be beneficial for embryogenesis induction, but also for plant regeneration, even in recalcitrant genotypes [20].

More recently, a triple combination of maltose, silver nitrate, and activated charcoal allowed for an increase in embryo yield of 3.9 times (production of up to 320 embryos and 200 plantlets/100 anthers) compared to the original medium [34]. The higher efficiency was associated with a positive synergistic effect of the three compounds in direct embryogenesis, embryo quality and other parameters related to the embryogenic response. In the same work, the first protocol for eggplant anther culture in liquid medium was developed, which resulted in up to 42 embryos per 100 anthers [34]. This medium was also based in the Dumas de Vaulx and Chambonnet method but supplemented with maltose and silver nitrate.

Further variations in Dumas de Vaulx protocol have shown that the treatment with other plant regulators during embryogenesis induction can also be efficient for the production of embryo-derived plantlets in certain cultivars. The replacement of kinetin by $1 \mathrm{mg} / \mathrm{L}$ zeatin riboside resulted in a percentage of responsive anthers of up to $27.8 \%$ [28]. It was also shown that there is a strong interaction between the genotype and the growth regulators used [29]. Other combinations of stress and induction medium have also been shown to be effective in anther culture. Embryo development was induced by preculturing anthers at 5-6 ${ }^{\circ} \mathrm{C}$ in MS medium supplemented with $1.0 \mathrm{mg} / \mathrm{L} \mathrm{2,4-D}$ and $1.0 \mathrm{mg} / \mathrm{L}$ kinetin [21]. The use of Gamborg (B5) salts as basal medium, supplemented with phenylacetic acid (PAA) was also found to be positive in terms of anther culture response [25].

Despite its advantages, anther culture still has some limitations. The most important is the possibility, at least theoretically, of inducing the occurrence of somatic embryos developed from anther tissues other than microspores. In parallel to the development of microspore-derived embryos, calli may emerge from the anthers upon exposure of the anther to the in vitro culture conditions [39]. These calli may have either microspore or somatic origin. Thus, although the first could be used to regenerate haploid or DH plants, it would be necessary to analyze their origin with molecular markers in order to identify somatic calli and discard them. Additionally, somatic calli consume resources and space, which may affect the growth of true microspore-derived embryos. The region of the wound produced when anthers are excised from the filament is especially prone to proliferation as undifferentiated callus masses.

An additional problem is the lack of control of the substances secreted by the anther wall layers surrounding the pollen sac. Some of them may have a positive effect on the induction and regeneration of androgenic embryos, but many others, principally coming from the degradation of these tissues, may have detrimental and undesired effects [8]. 
In many cases, these problems may have a relative effect on the final yield of DHs, and there may not be a need for solving them. However, in other cases these limitations make anther culture inefficient. In these cases, isolated microspore culture may constitute a suitable alternative.

\section{In Vitro Culture of Isolated Eggplant Microspores}

In isolated microspore cultures, microspores/young pollen are isolated from the donor anthers. They are the only cell types present in the culture and, therefore, the only possible origin for the regenerated plants. Other advantages of microspore cultures include an increase in the efficiency of embryo production, since embryos are not constrained by the reduced space of the anther locule, and a better control of medium conditions, since no other tissues are present and cannot modify the medium composition by the secretion of beneficial or harmful compounds. Freely suspended microspores are also amenable for transformation by biolistic techniques, or combined biolistic and Agrobacterium-mediated transformation, by using plasmids, short peptide nanocarriers and cell penetrating peptides [40-42].

In the first attempt to establish an isolated microspore culture protocol in eggplant, isolated late uninucleated microspores and young pollen grains belonging to three different F1 cultivars were subjected to a combination of both starvation and heat stress, which resulted in the generation of microspore-derived structures with an efficiency higher than by anther culture-based protocols [19]. This protocol, however, produced no embryos but calli with different levels of ploidy and a limited ability for shoot regeneration from them. This initial protocol has served as the basis for the different modifications made subsequently. Briefly, isolated microspores (Figure 2A) are incubated at $35^{\circ} \mathrm{C}$ during three days suspended in distilled water under dark conditions. The combination of heat stress and full nutrient starvation promotes the developmental switch in a percentage of microspores higher than with anther culture. Such a switch is revealed by an increase in size of induced microspores (Figure 2B), whereas the non-induced cells stop their growth and/or die. After the stress treatment, microspores are transferred to an NLNbased medium supplemented with 6-benzylaminopurine (BA) and naphthaleneacetic acid (NAA) and cultured continuously at $25^{\circ} \mathrm{C}$ in darkness. After 7-10 days, depending on the genotype and/or the growth conditions of donor plants, some microspores will show organized embryogenic cell divisions (Figure 2C,D) that end up with the formation of globular-like embryos. However, to our knowledge, it has not been possible up to now to promote the development of eggplant microspore-derived embryos beyond this stage up to the mature, cotyledonary stage in a reproducible manner. Microspore-derived structures keep their embryo identity up to the globular stage [24] and then they transform into proliferative but undifferentiated callus-like structures (Figure 2E,F). This situation is opposed to that of other species such as, for example, Brassica napus or tobacco, which develop true embryos. Regardless, these calli can be subcultured in regeneration medium to induce shoot and root organogenesis (Figure 2G) and, after acclimatization of the in vitro plants produced, fully functional DHs are obtained (Figure $2 \mathrm{H}$ ).

Despite the economic importance of eggplant, modifications of the different parts of this protocol to make it more efficient were not proposed until more than fifteen years later. The first aspect that influences the embryogenic response of microspores is the conditions under which the donor plants have been cultured, which influences further viability of microspores to a large extent. Indeed, the viability of eggplant microspores was found to be affected by the light intensity applied to donor plants, but not by slight (circa $6{ }^{\circ} \mathrm{C}$ ) temperature changes [35]. Interestingly, the viability of eggplant microspores was not dependent on light intensity at the moment of excision of the floral buds, but it was influenced by the amount of light that donor plants were exposed to during the two days prior to excision [35]. Moreover, although microelements such as boron has been shown to increase pollen quality in pepper [43], the foliar application of boron at low doses 
produced no effects in the viability of eggplant microspores, and notably reduced it at high doses [35].
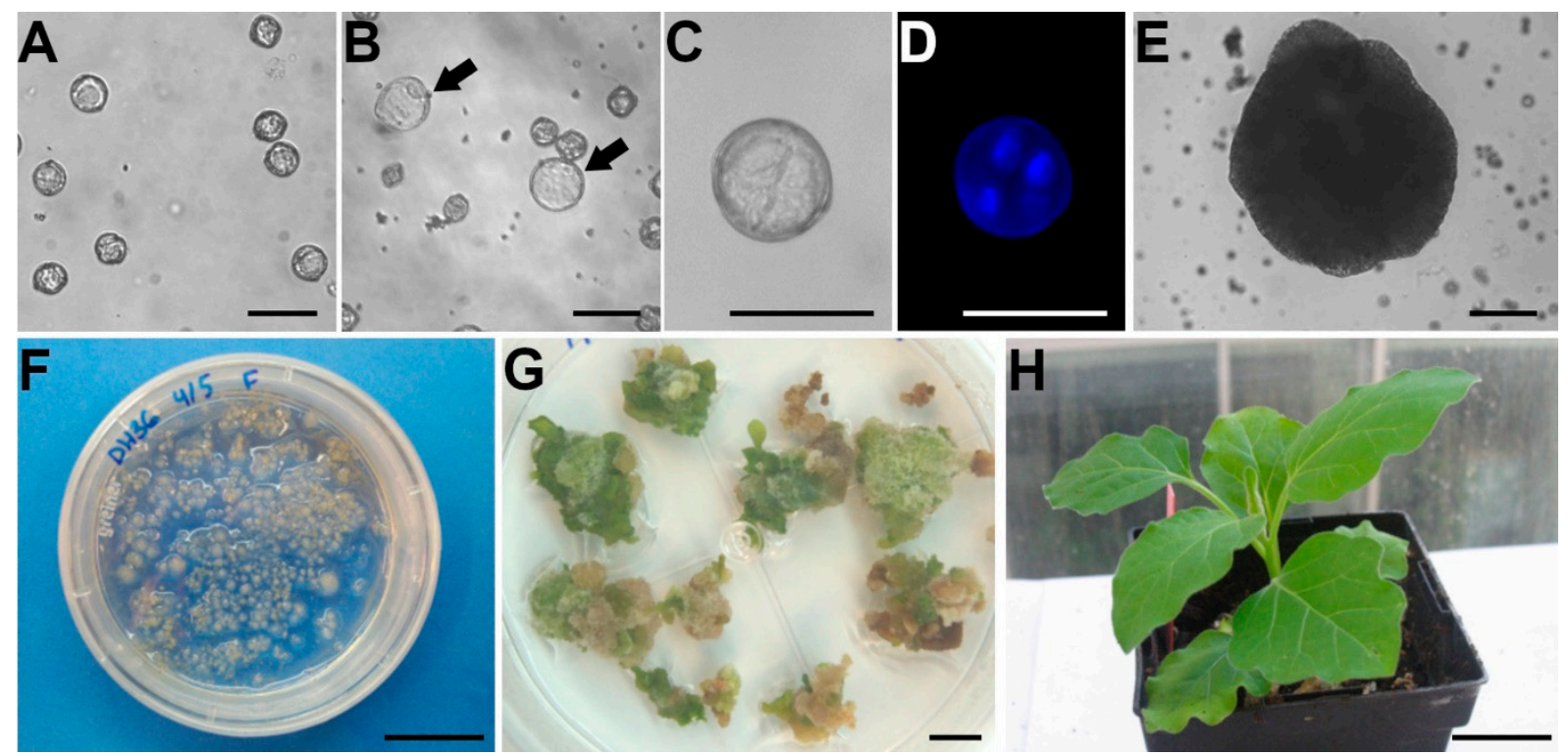

Figure 2. Isolated microspore culture in eggplant. (A). Microspores freshly isolated from eggplant anthers and cultured in vitro in liquid medium. (B). Cultured microspores after the induction treatment. Most microspores remain arrested, with no evident development, whereas others enlarge (arrows) as a consequence of embryogenesis induction. (C,D). Multicellular microspore-derived structure as seen under phase contrast (C) and DAPI staining for visualization of the nuclei (D). (E). Callus-like structure formed from a microspore-derived embryo in vitro culture. (F). Culture dish with microsporederived calli. (G). Regenerating calli where multiple green, organogenic nodules are seen on their surface. $(\mathbf{H})$. Acclimatized eggplant DH plant obtained through microspore culture. Bars: A-E: $50 \mu \mathrm{m} ; \mathrm{F}, \mathrm{G}: 1 \mathrm{~cm} ; \mathrm{H}: 5 \mathrm{~cm}$.

Once microspores are isolated and prior to culture initiation, microspores must be suspended in the liquid medium at a defined density in order to optimize the efficiency. A microspore density between $1 \times 10^{5}$ and $5 \times 10^{5}$ microspores $/ \mathrm{mL}$ was initially proposed [19]. Recently, a more detailed assay was performed to narrow down this range of cell densities [35]. The highest number of microspore-derived calli was produced when microspores were cultured at densities between $2 \times 10^{5}$ and $3 \times 10^{5}$. Lower densities (i.e., $5 \times 10^{4}$ ) produced no calli at all. In turn, higher densities (i.e., $2 \times 10^{6}$ ) resulted systematically in the growth of bacterial colonies, possibly endophytes released from anther tissues during the process of microspore isolation.

Efforts have also been devoted to the optimization of in vitro culture conditions. In different eggplant genotypes, positive effects on the embryogenic response have been observed with different modifications of the initial culture medium, including the addition, alone or in combination, of growth regulators such as abscisic acid and epibrassinolide, and of biopolymers such as polyethylene glycol, arabinogalactans and arabinogalactan proteins [26]. Additionally, a reduction in NAA and BA was found to be beneficial to increase the rate of embryogenesis induction [26]. However, the main bottleneck of microspore embryogenesis through microspore culture in eggplant is still the difficulty of microspore-derived embryos in undergoing a true transition from globular to bipolar, differentiated embryos. Although the exact reason for the development of callus-like structures is still unknown, it seems likely due to a suboptimal medium composition where some components, probably growth regulators, are not properly balanced. In this sense, a reduction in growth regulators in the culture medium has been shown to increase the occurrence of structures anatomically closer to true embryos, rather than to callus-like structures (manuscript in preparation). Surely, future research should focus on this stage. Finally, plant regeneration through shoot and root organogenesis has also been improved 
using different relative amounts of IAA and zeatin in the regeneration medium, thereby increasing the frequency of organogenesis [24,27].

\section{The Critical Role of the Genotype in the Embryogenic Response of Eggplant Microspores}

Aside from the growth conditions of donor plants and the particular in vitro culture conditions used, the most determinant factor for an efficient production of androgenic $\mathrm{DHs}$, either by anther culture or by isolated microspore culture, is the genotype of donor plants. In all the species studied, there are varieties or genotypes that are responsive to embryogenesis whereas others are very recalcitrant. In the case of eggplant, a study of 12 different accessions of common eggplant and related materials from the primary genepool (the eggplant complex) and the secondary genepool showed that only common eggplant (Solanum melongena) materials responded to microspore embryogenesis [39]. Wild relatives and even their crosses with common eggplant materials showed no response. This is not surprising, since microspore embryogenesis does not occur in nature, and wild species have not been selected during their evolution to become more efficient for this trait. Instead, it is possible that some of the responding genotypes, in particular the $F_{1}$ hybrids, were subjected to anther culture during the breeding programs they come from. Indeed, the two best performing genotypes of the study (Bandera and Ecavi) are commercial $F_{1}$ hybrids [39]. This was confirmed in a later study where microspores of these accessions were isolated and cultured in vitro. The three responding genotypes were Bandera, Ecavi, and Cristal, the three commercial $\mathrm{F}_{1}$ hybrids tested [24].

As for any other genetic trait, the embryogenic competence of eggplant microspores segregates in the offspring of $\mathrm{F}_{1}$ hybrids. Indeed, an eggplant $\mathrm{DH}$ population was developed from the $F_{1}$ hybrid Bandera [30]. It was found that, in addition to segregation of several morphological and reproductive traits, the androgenic response also showed variation among DH lines, from null to very high. One of these lines (DH36) was very similar to Bandera in anatomy and reproductive competence but produced up to four times more microspore-derived calli than Bandera in a stable manner. DH36 has then been used for other studies aimed at optimizing the protocol of microspore culture. It was found that its response to changes in the in vitro conditions differed from other $F_{1}$ hybrids, possibly due to the different steps of in vitro selection undergone by this line. For example, it was found that when the concentration of basal salts and sucrose was increased and the concentration of growth regulators was reduced, the number of microspore-derived calli produced by DH36 decreased, whereas it was remarkably increased in the two different $F_{1}$ hybrids [35]. These studies demonstrated the genetic basis of the embryogenic competence of eggplant microspores and illustrated how this trait can be improved. However, only few data are available about the cellular, molecular, or physiological basis for embryogenic competence in eggplant.

One of the reasons for the lower embryogenic response of eggplant, when compared to other species such as B. napus, may relate to intracellular $\mathrm{Ca}^{2+}$ levels. A peak of $\mathrm{Ca}^{2+}$ accumulation was observed in vacuolated microspores and young pollen (the stages inducible to embryogenesis) of the highly embryogenic B. napus DH4079 line, whereas in equivalent stages of the eggplant DH36 line, $\mathrm{Ca}^{2+}$ levels were much lower [31]. Later on it was found that a callose-rich subintinal layer was formed in embryogenic microspores of both $B$. napus and eggplant lines, but it was thicker and richer in callose in microspores of the highly embryogenic $B$. napus line and thinner and less callose-rich in eggplant microspores [32]. Microspores of the high response B. napus line with thicker subintinal layers exhibited a higher protection against osmotic stress and increased viability when cultured in vitro in liquid medium [32]. Thus, it seemed that the subintinal layer confers a protection against osmotic stress at least, which increases the viability of in vitro cultured microspores and therefore their chance to become embryogenic. A low response B. napus line (DH12075) was also analyzed in parallel with the high response B. napus DH4079 line and the DH36 eggplant line. Interestingly, the results of the low response B. napus line were remarkably similar to those of the eggplant line, both showing lower $\mathrm{Ca}^{2+}$ levels and 
thinner subintinal layers with less callose and lower embryogenic competence than the high response B. napus line [32].

These findings relate the presence of the callose-rich subintinal layer with the embryogenic competence, being greater in high-response genotypes. Callose deposition in the subintinal layer was found to be $\mathrm{Ca}^{2+}$-dependent [32], which established a link between high $\mathrm{Ca}^{2+}$ levels in the microspore/pollen stages inducible to embryogenesis, the formation of a callose-rich, protective subintinal layer, and a high embryogenic response. In the case of eggplant, lower $\mathrm{Ca}^{2+}$ levels in the inducible stages would account for the formation of a thinner subintinal layer, where callose is deposited in lower amounts. Such a layer in eggplant microspores would be less protective against osmotic stress, and this would explain the dramatic decrease in viability observed in cultured microspores after the inductive treatment (our unpublished observations) and their eventual lower embryogenic competence. According to this, it could be speculated that, as in B. napus, the differences in embryogenic response among eggplant genotypes could be related to similarly different levels of intracellular $\mathrm{Ca}^{2+}$ and therefore a different ability to form a protective subintinal layer.

\section{Genome Doubling of Haploid Individuals}

Microspore-derived haploid embryos can produce weak and sterile plants. To prevent this, their chromosome set, whether maternal (gynogenesis) or paternal (androgenesis), must undergo genome duplication in order to become true DHs [44,45]. Mainly, cellular processes such as nuclear fusion are the cause of spontaneous genome doubling [45,46], and their occurrence is highly dependent on plant species. For instance, species such as Hordeum vulgare [47], Sorghum bicolor [48], Brassica oleraceae var italica [49] and Solanum tuberosum [50] show a direct, spontaneous genome doubling rate higher than $90 \%$, whereas species like Triticum aestivum [51], Oryza sativa [52,53], Cucumis sativus [54], Cucumis melo [53], Allium cepa [55], or Beta vulgaris [56,57] are recalcitrant to genome doubling. Nevertheless, protocols to induce indirect genome doubling with the aid of drugs are needed for both types of species in order to efficiently exploit the potential of DH technology.

Indirect genome doubling protocols are mainly based on the application of antimitotic compounds that inhibit microtubule polymerization, resulting in defective microtubulebased structures (the mitotic spindle and the phragmoplast) and eventually in abnormal chromosome segregation when applied at high doses and in nuclear fusion when applied at low doses [45]. Colchicine is a naturally occurring, antimitotic compound traditionally used to induce polyploidy in diploid species, and to induce doubled haploidy in haploid individuals. In fact, it is the preferred drug for genome doubling in haploids. However, its toxic effects on animal (including human) cells and for the environment has boosted the search for other antimitotic compounds, such as the dinitroaniline-based herbicides oryzalin, trifluralin and amiprophos-methyl. Specific protocols with different drugs, doses, and application modes under in vitro and in vivo conditions have been recently reviewed $[44,58]$. Specifically, eggplant shows a moderate ability to undergo genome doubling without using any drug. In some backgrounds a percentage close to $45 \%$ was reported [34], whereas in others it reached 60\% [24]. Genome doubling in eggplant seems also to be influenced by the in vitro culture time of haploid seedlings, so the longer they remain in vitro, the higher the doubling rates [39].

The protocols for induction of genome doubling when haploid plants are still in vitro typically include the use of $0.5-1 \%$ aqueous solutions of colchicine. For example, the best performing treatments for eight different eggplant backgrounds were reported to be $0.5 \%$ colchicine for $2 \mathrm{~h}$ and $1 \%$ colchicine for $1 \mathrm{~h}$ [22]. For acclimated, ex vitro haploid plants, the application of $0.5 \%$ colchicine dissolved in lanolin paste for two days has been reported successful to induce doubling in axillary buds [59]. Thick lanolin paste is used to avoid liquid colchicine evaporation and draining away from the bud. With this method it was possible to increase the production of $\mathrm{DH}$ plants by an additional $25 \%$ with respect to the rate of direct genome doubling [24]. 
Moreover, in our experience, the rate of direct genome doubling without using antimitotic drugs varies enormously among eggplant materials. When using new, untested materials, the most reasonable starting point would be to evaluate what the direct genome doubling rate is, and only when it does not meet the particular needs of the experiments, try different combinations of colchicine concentrations and times. If colchicine does not produce the necessary frequency of genome doubling in $\mathrm{DH}$ plants, or if special regulations against the use of colchicine operate, other antimitotics should be tried.

\section{Use of DHs for Eggplant Breeding Programs}

Doubled haploid (DH) technology for plant breeding has been around since the 1970s, and this technology was used to obtain DH lines initially in B. napus [60] and barley [61]. From these pioneer findings, androgenic DHs have been used to produce commercial varieties in many other species such as wheat, other Brassica species, rice, melon, asparagus, as well as Solanaceae including pepper, tobacco, or eggplant, which has resulted in the generation of more than 300 new varieties [62,63]. Eggplant breeding programs are mostly focused on the release of hybrid varieties with improved traits [59]. Eggplant F1 hybrids, resulting from the crossing of two parental homozygous plants, typically perform better than parental lines for different agronomic traits [5,64]. A great amount of effort has been devoted to evaluating the performance of eggplant F1 hybrids for different characteristics, using wild or local homozygous landraces as parental lines [5,65-67]. Among others, the valuable agronomic objective of eggplant breeding programs are yield, fruit color, seed/pulp ratio, flesh consistency and browning, nutritional characteristics, and resistance to diseases [59].

Breeding for disease resistance is important since commercial eggplant cultivars are known to have limited resistance to disease [68]. In this context, anther culture, the DH technology most developed and widely applicable in eggplant, has been routinely used by private seed companies since the end of the 1980s, soon after the discovery of the method of Dumas de Vaulx and Chambonnet, to produce pure lines as part of their eggplant breeding programs $[59,68]$. It is therefore likely that many of the current varieties have benefited from this technique. Recently driven by the challenge of climate change, there has been an increasing interest in eggplant research, principally focused on the use of wild eggplant relatives to develop new varieties with improved resistance to bacterial wilt, as well as drought and heat, which will surely contribute to the generation of new and improved cultivars.

Anther culture has also been used to reduce the ploidy of tetraploids, thereby producing dihaploid progenies as, for example, in tetraploid interspecific hybrids S. melongena $\times$ S. integrifolium and S. melongena cv. Dourga $\times$ S. aethiopicum [69-72]. The dihaploid lines were then used to introgress Fusarium oxysporum resistance genes and their nutraceutical and health-promoting compounds were characterized, proving successful as an approach to obtain new eggplant genotypes with useful traits derived from related species.

Other than the generation of eggplant hybrid lines, DH technology has contributed to both the mapping of interesting agronomical traits and the generation of genetic variability. For example, DH populations have been used to detect quantitative trait loci (QTLs) related with resistance to Ralstonia pseudosolanacearum [73], and yield-related loci [74]. Genetic variation among eggplant DHs lines is produced using both inbred cultivars and heterozygous lines as donor plants [59]. Specifically, the phenotypic segregation of leaf, flower, and fruit traits, including fruit set, seed setting, and germination rate, was studied in a $\mathrm{DH}$ population obtained from a commercial $\mathrm{F}_{1}$ hybrid [30]. Moderate morphological variability was observed in this study. The presence of prickles in the fruit calix was found to be one of the most variable phenotypes, as individuals from the DH population showed significantly fewer prickles than the $\mathrm{F}_{1}$ donor line. Additionally, flower color, the number of flowers per inflorescence, and primary and secondary fruit colors presented moderate to high variability. The DH population also showed a slightly reduced reproductive 
ability when selfed compared with the $\mathrm{F}_{1}$ [30]. On the other hand, a study of genes from Solanum aethiopicum introgressed in S. melongena revealed that anther cultures generate $\mathrm{DH}$ populations with massive segregation distortion, which limits the usefulness of the method to preserve all the genetic variation of the parental lines [75].

In summary, $\mathrm{DH}$ technology and principally anther culture still has some practical limitations when applied to eggplant breeding. However, DH technology has shown substantial potential to assist breeders, not only for the generation of hybrid varieties, but also to gain genetic variability and to identify QTLs associated with agronomically important traits. Therefore, it is expected to be used in the future as part of current breeding strategies to deal with increasing food demand, the emergence of new pests, as well as biotic and abiotic stresses caused by global warming.

\section{Limitations of DH Technology and Future Perspectives}

To the best of our knowledge, the only DH technologies that have consistently yielded positive results in eggplant have been microspore culture and, principally, anther culture. Eggplant DH populations produced by these methods must generate sufficient genetic variability to be useful to produce pure lines for hybrid seed production, and the possible occurrence of significant segregation distortion should be evaluated in each $\mathrm{DH}$ population. These two techniques, based on in vitro androgenesis, also present the limitations typical of any other in vitro culture process. The most important, as mentioned above, is the genotype. In addition, the low efficiency of embryo induction and the need for checking the origin of all the plants regenerated from anther cultures, and the current inability to obtain mature, germinating microspore-derived embryos from microspore cultures, have restricted the practical large-scale implementation of these methods for hybrid seed production. Finally, the limited knowledge of the cellular, molecular, and genetic mechanisms controlling recalcitrance in different genotypes is also a relevant obstacle to increase the efficiency of these processes. These techniques still have room for improvement, principally microspore culture and the undesirable transformation of microspore-derived embryos into calli. However, microspore embryogenesis will always depend on the genotype of donor plants to a large extent.

As an alternative to in vitro-based approaches, the possibility of generating haploid inducer lines seems more and more feasible. In the last decade, the manipulation of certain genes has allowed for the production of haploid inducer lines in different species. In maize, mutations in genes like NOT LIKE DAD (NLD)/MATRILINEAL (MATL)/patatinlike phospholipase-A1 (PLA1) or DOMAIN OF UNKNOWN FUNCTION 679 (DMP) have consistently generated lines that, when crossed with elite materials, produce haploids with the genome of the elite line [76,77]. Unfortunately, NLD/MATL/ZmPLA1 does not have homologs in dicots, but the dicot Arabidopsis thaliana has multiple DMP-like homologs, and one of the double mutants generated (atdmp8-/-atdmp9-/-) was shown to induce haploids when crossed [78]. It seems reasonable that other dicots such as eggplant may also have $D M P$-like homologs.

However, the most promising gene to mutate in order to generate haploid inducer lines in dicots such as eggplant is the gene of the centromeric histone $\mathrm{H} 3$ (CENH3). This approach was first described in Arabidopsis thaliana [79]. It consists of editing the centromere-targeting domain of CENH3 and the crossing of these mutants with wild type individuals. Then, during the early stages of embryogenesis, the mutant genome with inactivated centromeres is eliminated and an embryo bearing only the chromosomes from the wild-type parental is developed [80]. The cenh3 mutants were first produced by genetic transformation, but they are currently also produced through gene editing and also by EMS-driven mutagenesis [81]. Haploid-producing cenh 3 mutants have already been reported for different crops, including maize and wheat [82-84], and the method has also been tested in red cabbage [85], barley, and sugar beet [86]. There are also patents and inventions that claim to have developed similar systems in other agronomically interesting crops by CENH3 manipulation, but also by alteration of other components of the kinetochore complex (reviewed in [80]). 
As seen, intensive research is being done in this field as this system could be potentially useful to obtain haploids and then DHs in species described as recalcitrant for anther or microspore cultures [87]. In this sense, eggplant could be a suitable candidate, as its genome has already been recently sequenced and assembled [88,89], and there are already protocols available for genetic transformation (reviewed in [90,91]) and gene editing [92]. This alternative could overcome the limitations imposed by the genotype for in vitro-based methods, the only approaches explored so far, and could therefore be useful for a broader range of eggplant materials.

Despite the possibilities of these promising technologies, the final implementation of these techniques to assist in eggplant breeding programs will eventually be, as in many other cases in applied research, dependent on funding. Each seed company should determine to what extent the economic return of the use of these techniques in their eggplant programs justifies the initial investments that must be made to implement them. In addition, legal considerations must also be taken into account, at least in the case of gene editing. Although it is authorized in some countries worldwide, in others, such as those of the European Union, they are still banned. It appears paradoxical in a case like this, where the edited mutant is only used as an inducer, and the final product does not even contain a single trace of the edited genes.

\section{Conclusions}

Anther culture is the most widely used and easy method to produce DH plants in eggplant. Isolated microspore culture, although more technically challenging, has additional advantages that make it worth implementing. However, problems such as the transformation of embryos into calli and the identification of an efficient and universal method for genome doubling are still to be solved. In recent decades, DH technology (anther culture principally) has been used in different eggplant breeding programs. Eggplant could be a suitable candidate for the future development of haploid inducer lines through CRISPR/Cas9 gene editing.

Author Contributions: Conceptualization, validation, resources, data curation, writing-original draft preparation, writing—review and editing, visualization, R.M., A.C.-S., and J.M.S.-S.; supervision, project administration, funding acquisition, R.M. and J.M.S.-S. All authors have read and agreed to the published version of the manuscript.

Funding: This research was funded by the Valencian Government, grant number CDEIGENT 2018/023 to RMM and by the Spanish MICINN, grant number PID2020-115763RB-I00 to JMSS. ACS is the recipient of a predoctoral contract from the FPU program of the Spanish Government.

Institutional Review Board Statement: Not applicable.

Informed Consent Statement: Not applicable.

Data Availability Statement: Data sharing is not applicable to this article.

Conflicts of Interest: The authors declare no conflict of interest.

\section{References}

1. Knapp, S.; Aubriot, X.; Prohens, J. Eggplant (Solanum melongena L.): Taxonomy and relationships. In The Eggplant Genome; Chapman, M.A., Ed.; Springer International Publishing: Cham, Switzerland, 2019; pp. 11-22.

2. Wang, J.X.; Gao, T.G.; Knapp, S. Ancient Chinese literature reveals pathways of eggplant domestication. Ann. Bot. 2008, 102, 891-897. [CrossRef] [PubMed]

3. Taher, D.; Solberg, S.; Prohens, J.; Chou, Y.Y.; Rakha, M.; Wu, T.H. World vegetable center eggplant collection: Origin, composition, seed dissemination and utilization in breeding. Front. Plant Sci. 2017, 8, 1484. [CrossRef]

4. FAOSTAT. Available online: http://www.fao.org/faostat (accessed on 2 May 2021).

5. Kumar, A.; Sharma, V.; Jain, B.T.; Kaushik, P. Heterosis breeding in eggplant (Solanum melongena L.): Gains and provocations. Plants 2020, 9, 403. [CrossRef]

6. Prigge, V.; Xu, X.; Li, L.; Babu, R.; Chen, S.; Atlin, G.N.; Melchinger, A.E. New insights into the genetics of in vivo induction of maternal haploids, the backbone of doubled haploid technology in maize. Genetics 2012, 190, 781-793. [CrossRef] 
7. Yan, G.; Liu, H.; Wang, H.; Lu, Z.; Wang, Y.; Mullan, D.; Hamblin, J.; Liu, C. Accelerated generation of selfed pure line plants for gene identification and crop breeding. Front. Plant Sci. 2017, 8, 1786. [CrossRef] [PubMed]

8. Seguí-Simarro, J.M. Androgenesis in solanaceae. In In Vitro Embryogenesis; Germanà, M.A., Lambardi, M., Eds.; Methods in Molecular Biology; Springer Science + Business Media: New York, NY, USA, 2016; Volume 1359, pp. $209-244$.

9. Ren, J.; Wu, P.; Trampe, B.; Tian, X.; Lübberstedt, T.; Chen, S. Novel technologies in doubled haploid line development. Plant Biotechnol. J. 2017, 15, 1361-1370. [CrossRef] [PubMed]

10. Gilles, L.M.; Martinant, J.-P.; Rogowsky, P.M.; Widiez, T. Haploid induction in plants. Curr. Biol. 2017, 27, R1095-R1097. [CrossRef]

11. Seguí-Simarro, J.M.; Belinchón Moreno, J.; Guillot Fernández, M.; Mir, R. Species with haploid or doubled haploid protocols. In Doubled Haploid Technology Vol. 1. General Topics, Alliaceae, Cereals; Seguí-Simarro, J.M., Ed.; Methods in Molecular Biology; Springer Science + Business Media: New York, NY, USA, 2021; Volume 2287, pp. 41-103.

12. Guha, S.; Maheshwari, S.C. In vitro production of embryos from anthers of Datura. Nature 1964, 204, 497. [CrossRef]

13. Seguí-Simarro, J.M.; Corral-Martínez, P.; Parra-Vega, V.; González-García, B. Androgenesis in recalcitrant solanaceous crops. Plant Cell Rep. 2011, 30, 765-778. [CrossRef] [PubMed]

14. Seguí-Simarro, J.M.; Nuez, F. Embryogenesis induction, callogenesis, and plant regeneration by in vitro culture of tomato isolated microspores and whole anthers. J. Exp. Bot. 2007, 58, 1119-1132. [CrossRef]

15. Raina, S.K.; Iyer, R.D. Differentiation of diploid plants from pollen callus in anther cultures of Solanum melongena L. Z. Pflanzenzüchtg. 1973, 70, 275-280.

16. Chinese Research Group of Haploid Breeding. Induction of haploid plants of Solanum melongena. In Proceedings of the Symposium on Plant Tissue Culture, 25-30 May 1978, Peking, China; Science Press: Peking, China, 1978; pp. 227-232.

17. Gu, S.-R. Plantlets from isolated pollen cultures of eggplant (Solanum melongena L.). Acta Bot. Sin. 1979, $21,30-36$.

18. Dumas de Vaulx, R.; Chambonnet, D. Culture in vitro d'anthères d'aubergine (Solanum melongena L.): Stimulation de la production de plantes au moyen de traitements à $35^{\circ} \mathrm{C}$ associés à de faibles teneurs en substances de croissance. Agronomie 1982, 2, 983-988. [CrossRef]

19. Miyoshi, K. Callus induction and plantlet formation through culture of isolated microspores of eggplant (Solanum melongena L.). Plant Cell Rep. 1996, 15, 391-395. [CrossRef]

20. Gémes-Juhasz, A.; Venczel, G.; Sagi, Z.S.; Gajdos, L.; Kristof, Z.; Vagi, P.; Zatyko, L. Production of doubled haploid breeding lines in case of paprika, spice paprika, eggplant, cucumber, zucchini and onion. Acta Hortic. 2006, 725, 845-854. [CrossRef]

21. Liu, D.C.; Fang, C.; Li, Y.J.; Liu, X.J.; Liang, G.Y. Studies on the anther culture technology system for eggplant (Solanum melongena L.). Southwest China J. Agric. Sci. 2008, 21, 1643-1646.

22. Başay, S.; Şeniz, V.; Ellialtioğlu, Ş. Obtaining dihaploid lines by using anther culture in the different eggplant cultivars. J. Food Agric. Environ. 2011, 9, 188-190.

23. Salas, P.; Rivas-Sendra, A.; Prohens, J.; Seguí-Simarro, J.M. Influence of the stage for anther excision and heterostyly in embryogenesis induction from eggplant anther cultures. Euphytica 2012, 184, 235-250. [CrossRef]

24. Corral-Martínez, P.; Seguí-Simarro, J.M. Efficient production of callus-derived doubled haploids through isolated microspore culture in eggplant (Solanum melongena L.). Euphytica 2012, 187, 47-61. [CrossRef]

25. Ozdemir, B.; Onus, N. The effects of phenylacetic acid (PAA) on haploid embryo induction in eggplant (Solanum melongena L.) anther culture. In Proceedings of the Breakthroughs in the Genetics and Breeding of Capsicum and Eggplant, Torino, Italy, 2-4 September 2013.

26. Corral-Martínez, P.; Seguí-Simarro, J.M. Refining the method for eggplant microspore culture: Effect of abscisic acid, epibrassinolide, polyethylene glycol, naphthaleneacetic acid, 6-benzylaminopurine and arabinogalactan proteins. Euphytica 2014, 195, 369-382. [CrossRef]

27. Rivas-Sendra, A.; Corral-Martínez, P.; Camacho-Fernández, C.; Seguí-Simarro, J.M. Improved regeneration of eggplant doubled haploids from microspore-derived calli through organogenesis. Plant Cell Tissue Organ Cult. 2015, 122, 759-765. [CrossRef]

28. Emrani Dehkehan, M.; Moieni, A.; Movahedi, Z. Effects of zeatin riboside, mannitol and heat stress on eggplant (Solanum melongena L.) anther culture. Iran. J. Genet. Plant Breed. 2017, 6, 16-26. [CrossRef]

29. Emrani Dehkehan, M.; Moieni, A.; Movahedi, Z. Effects of BAP, Kin and $\mathrm{NH}_{4} \mathrm{NO}_{3}$ concentration on the eggplant anther culture (Solanum melongena L.). Iran. J. Field Crop Sci. 2017, 48, 877-888. [CrossRef]

30. Rivas-Sendra, A.; Campos-Vega, M.; Calabuig-Serna, A.; Seguí-Simarro, J.M. Development and characterization of an eggplant (Solanum melongena) doubled haploid population and a doubled haploid line with high androgenic response. Euphytica 2017, 213, 89. [CrossRef]

31. Rivas-Sendra, A.; Calabuig-Serna, A.; Seguí-Simarro, J.M. Dynamics of calcium during in vitro microspore embryogenesis and in vivo microspore development in Brassica napus and Solanum melongena. Front. Plant Sci. 2017, 8, 1177. [CrossRef] [PubMed]

32. Rivas-Sendra, A.; Corral-Martínez, P.; Porcel, R.; Camacho-Fernández, C.; Calabuig-Serna, A.; Seguí-Simarro, J.M. Embryogenic competence of microspores is associated with their ability to form a callosic, osmoprotective subintinal layer. J. Exp. Bot. 2019, 70, 1267-1281. [CrossRef]

33. García-Fortea, E.; García-Pérez, A.; Gimeno-Páez, E.; Sánchez-Gimeno, A.; Vilanova, S.; Prohens, J.; Pastor-Calle, D. A deep learning-based system (microscan) for the identification of pollen development stages and its application to obtaining doubled haploid lines in eggplant. Biology 2020, 9, 272. [CrossRef] 
34. Vural, G.E.; Ari, E. Triple synergistic effect of maltose, silver nitrate and activated charcoal on high embryo yield of eggplant (Solanum melongena L.) anther cultures. Sci. Hortic. 2020, 272, 109472. [CrossRef]

35. Rivas-Sendra, A.; Corral-Martínez, P.; Camacho-Fernández, C.; Porcel, R.; Seguí-Simarro, J.M. Effects of growth conditions of donor plants and in vitro culture environment in the viability and the embryogenic response of microspores of different eggplant genotypes. Euphytica 2020, 216, 167. [CrossRef]

36. Seguí-Simarro, J.M. Androgenesis revisited. Bot. Rev. 2010, 76, 377-404. [CrossRef]

37. Rotino, G.L. Anther culture in eggplant (Solanum melongena L.). In In Vitro Embryogenesis in Higher Plants; Germana, M.A., Lambardi, M., Eds.; Methods in Molecular Biology; Springer: New York, NY, USA, 2016; Volume 1359, pp. $453-466$.

38. Calabuig-Serna, A.; Porcel, R.; Corral-Martínez, P.; Seguí-Simarro, J.M. Anther and isolated microspore culture in eggplant (Solanum melongena L.). In Doubled Haploid Technology II: Hot Topics, Apiaceae, Brassicaceae, Solanaceae; Seguí-Simarro, J.M., Ed.; Methods in Molecular Biology; Springer Science + Business Media: New York, NY, USA, 2021; Volume 2288, pp. 235-250.

39. Salas, P.; Prohens, J.; Seguí-Simarro, J.M. Evaluation of androgenic competence through anther culture in common eggplant and related species. Euphytica 2011, 182, 261-274. [CrossRef]

40. Chugh, A.; Amundsen, E.; Eudes, F. Translocation of cell-penetrating peptides and delivery of their cargoes in triticale microspores. Plant Cell Rep. 2009, 28, 801-810. [CrossRef] [PubMed]

41. Eudes, F.; Shim, Y.-S.; Jiang, F. Engineering the haploid genome of microspores. Biocatal. Agric. Biotechnol. 2014, 3, 20-23. [CrossRef]

42. Abdollahi, M.R.; Corral-Martinez, P.; Mousavi, A.; Salmanian, A.H.; Moieni, A.; Seguí-Simarro, J.M. An efficient method for transformation of pre-androgenic, isolated Brassica napus microspores involving microprojectile bombardment and Agrobacteriummediated transformation. Acta Physiol. Plant. 2009, 31, 1313-1317. [CrossRef]

43. Peñaloza, P.; Toloza, P. Boron increases pollen quality, pollination, and fertility of different genetic lines of pepper. J. Plant Nutr. 2018, 41, 969-979. [CrossRef]

44. Hooghvorst, I.; Nogués, S. Chromosome doubling methods in doubled haploid and haploid inducer-mediated genome-editing systems in major crops. Plant Cell Rep. 2020. [CrossRef]

45. Seguí-Simarro, J.M.; Nuez, F. Pathways to doubled haploidy: Chromosome doubling during androgenesis. Cytogenet. Genome Res. 2008, 120, 358-369. [CrossRef]

46. Kasha, K.J. Chromosome doubling and recovery of doubled haploid plants. In Haploids in Crop Improvement II; Palmer, C.E., Keller, W.A., Kasha, K.J., Nagata, T., Lörz, H., Widholm, J.M., Eds.; Biotechnology in Agriculture and Forestry; Springer: Berlin/Heidelberg, Germany, 2005; Volume 56, pp. 123-152.

47. Li, H.C.; Devaux, P. High frequency regeneration of barley doubled haploid plants from isolated microspore culture. Plant Sci. 2003, 164, 379-386. [CrossRef]

48. Kumaravadivel, N.; Rangasamy, S.R.S. Plant regeneration from sorghum anther cultures and field evaluation of progeny. Plant Cell Rep. 1994, 13, 286-290. [CrossRef]

49. Yuan, S.; Su, Y.; Liu, Y.; Li, Z.; Fang, Z.; Yang, L.; Zhuang, M.; Zhang, Y.; Lv, H.; Sun, P. Chromosome doubling of microsporederived plants from cabbage (Brassica oleracea var. capitata L.) and broccoli (Brassica oleracea var. italica L.). Front. Plant Sci. 2015, 6. [CrossRef]

50. Greplová, M.; Polzerová, H.; Domkářová, J. Intra- and inter-specific crosses of Solanum materials after mitotic polyploidization in vitro. Plant Breed. 2009, 128, 651-657. [CrossRef]

51. Sood, S.; Dhawan, R.; Singh, K.; Bains, N.S. Development of novel chromosome doubling strategies for wheat $\times$ maize system of wheat haploid production. Plant Breed. 2003, 122, 493-496. [CrossRef]

52. Hooghvorst, I.; Ramos-Fuentes, E.; López-Cristofannini, C.; Ortega, M.; Vidal, R.; Serrat, X.; Nogués, S. Antimitotic and hormone effects on green double haploid plant production through anther culture of Mediterranean japonica rice. Plant Cell Tissue Organ Cult. 2018, 134, 205-215. [CrossRef]

53. Hooghvorst, I.; Ribas, P.; Nogués, S. Chromosome doubling of androgenic haploid plantlets of rice (Oryza sativa) using antimitotic compounds. Plant Breed. 2020, 134, 754-761. [CrossRef]

54. Claveria, E.; Garcia-Mas, J.; Dolcet-Sanjuan, R. Optimization of cucumber doubled haploid line production using in vitro rescue of in vivo induced parthenogenic embryos. J. Am. Soc. Hortic. Sci. 2005, 130, 555-560. [CrossRef]

55. Fayos, O.; Vallés, M.P.; Garcés-Claver, A.; Mallor, C.; Castillo, A.M. Doubled haploid production from Spanish onion (Allium сера L.) germplasm: Embryogenesis induction, plant regeneration and chromosome doubling. Front. Plant Sci 2015, 6. [CrossRef]

56. Gürel, S.; Gürel, E.; Kaya, Z. Doubled haploid plant production from unpollinated ovules of sugar beet (Beta vulgaris L.). Plant Cell Rep. 2000, 19, 1155-1159. [CrossRef] [PubMed]

57. Hansen, A.L.; Gertz, A.; Joersbo, M.; Andersen, S.B. Short-duration colchicine treatment for in vitro chromosome doubling during ovule culture of Beta vulgaris L. Plant Breed. 1995, 114, 515-519. [CrossRef]

58. Shariatpanahi, M.E.; Niazian, M.; Ahmadi, B. Methods for chromosome doubling. In Doubled Haploid Technology Vol. 1. General Topics, Alliaceae, Cereals; Seguí-Simarro, J.M., Ed.; Methods in Molecular Biology; Springer Science + Business Media: New York, NY, USA, 2021; Volume 2287, pp. 127-148.

59. Rotino, G.L. Haploidy in eggplant. In In Vitro Haploid Production in Higher Plants; Jain, S.M., Sopory, S.K., Veilleux, R.E., Eds.; Kluwer Academic Publishers: Dordrecht, The Netherlands, 1996; Volume 3, pp. 115-141. 
60. Thompson, K.F. Oil-seed rape. In Reports of the Plant Breeding Institute; Cambridge University Press: Cambridge, UK, 1972; pp. 94-96.

61. Ho, K.M.; Jones, G.E. Mingo barley. Can. J. Plant Sci. 1980, 60, 279-280. [CrossRef]

62. Dunwell, J.M. Haploids in flowering plants: Origins and exploitation. Plant Biotechnol. J. 2010, 8, 377-424. [CrossRef]

63. Germanà, M.A. Gametic embryogenesis and haploid technology as valuable support to plant breeding. Plant Cell Rep. 2011, 30, 839-857. [CrossRef]

64. Kaushik, P.; Plazas, M.; Prohens, J.; Vilanova, S.; Gramazio, P. Diallel genetic analysis for multiple traits in eggplant and assessment of genetic distances for predicting hybrids performance. PLoS ONE 2018, 13, e0199943. [CrossRef] [PubMed]

65. Rakha, M.; Namisy, A.; Chen, J.R.; El-Mahrouk, M.E.; Metwally, E.; Taha, N.; Prohens, J.; Plazas, M.; Taher, D. Development of interspecific hybrids between a cultivated eggplant resistant to bacterial wilt (Ralstonia solanacearum) and eggplant wild relatives for the development of rootstocks. Plants 2020, 9, 1405. [CrossRef] [PubMed]

66. Kumchai, J.; Wei, Y.C.; Lee, C.Y.; Chen, F.C.; Chin, S.W. Production of interspecific hybrids between commercial cultivars of the eggplant (Solanum melongena L.) and its wild relative S. torvum. Genet. Mol. Res. 2013, 12, 755-764. [CrossRef]

67. Rodríguez-Burruezo, A.; Prohens, J.; Nuez, F. Performance of hybrids between local varieties of eggplant (Solanum melongena) and its relation to the mean of parents and to morphological and genetic distances among parents. Eur. J. Hortic. Sci. 2008, 73, 76-83.

68. Daunay, M.-C. Eggplant. In Vegetables II: Fabaceae, Liliaceae, Solanaceae, and Umbelliferae; Prohens, J., Nuez, F., Carena, M.J., Eds.; Handbook of Plant Breeding; Springer New York: New York, NY, USA, 2008; Volume 2, pp. 163-220.

69. Rotino, G.L.; Mennella, G.; Fusari, F.; Vitelli, G.; Tacconi, M.G.; D'Alessandro, A.; Acciarri, N. Towards introgression of resistance to Fusarium oxysporum F. sp. melongenae from Solanum integrifolium into eggplant. In Proceedings of the 11th Eucarpia Meeting on Genetics and Breeding of Capsicum and Eggplant, Antalya, Turkey, 9-13 April 2001; pp. 303-307.

70. Mennella, G.; Rotino, G.L.; Fibiani, M.; D'Alessandro, A.; Francese, G.; Toppino, L.; Cavallanti, F.; Acciarri, N.; Lo Scalzo, R. Characterization of health-related compounds in eggplant (Solanum melongena L.) lines derived from introgression of allied species. J. Agric. Food Chem. 2010, 58, 7597-7603. [CrossRef]

71. Rizza, F.; Mennella, G.; Collonnier, C.; Shiachakr, D.; Kashyap, V.; Rajam, M.V.; Prestera, M.; Rotino, G.L. Androgenic dihaploids from somatic hybrids between Solanum melongena and S. aethiopicum group Gilo as a source of resistance to Fusarium oxysporum $\mathrm{f}$. sp. melongenae. Plant Cell Rep. 2002, 20, 1022-1032. [CrossRef]

72. Rotino, G.L.; Sihachakr, D.; Rizza, F.; Vale, G.; Tacconi, M.G.; Alberti, P.; Mennella, G.; Sabatini, E.; Toppino, L.; D'Alessandro, A.; et al. Current status in production and utilization of dihaploids from somatic hybrids between eggplant (Solanum melongena L.) and its wild relatives. Acta Physiol. Plant. 2005, 27, 723-733. [CrossRef]

73. Salgon, S.; Raynal, M.; Lebon, S.; Baptiste, J.-M.; Daunay, M.-C.; Dintinger, J.; Jourda, C. Genotyping by sequencing highlights a polygenic resistance to Ralstonia pseudosolanacearum in Eggplant (Solanum melongena L.). Int. J. Mol. Sci. 2018, 19, 357. [CrossRef]

74. Portis, E.; Barchi, L.; Toppino, L.; Lanteri, S.; Acciarri, N.; Felicioni, N.; Fusari, F.; Barbierato, V.; Cericola, F.; Valè, G. QTL mapping in eggplant reveals clusters of yield-related loci and orthology with the tomato genome. PLoS ONE 2014, 9, e89499. [CrossRef]

75. Barchi, L.; Lanteri, S.; Portis, E.; Stagel, A.; Vale, G.; Toppino, L.; Rotino, G.L. Segregation distortion and linkage analysis in eggplant (Solanum melongena L.). Genome 2010, 53, 805-815. [CrossRef] [PubMed]

76. Thondehaalmath, T.; Kulaar, D.S.; Bondada, R.; Maruthachalam, R. Understanding and exploiting uniparental genome elimination in plants: Insights from Arabidopsis thaliana. J. Exp. Bot. 2021. [CrossRef] [PubMed]

77. Jacquier, N.M.A.; Gilles, L.M.; Martinant, J.-P.; Rogowsky, P.M.; Widiez, T. The maize in planta haploid induction lines, a corner stone for doubled haploid technology. In Doubled Haploid Technology II: Hot Topics, Apiaceae, Brassicaceae, Solanaceae; Seguí-Simarro, J.M., Ed.; Methods in Molecular Biology; Springer Science + Business Media: New York, NY, USA, 2021; Volume 2288.

78. Zhong, Y.; Chen, B.; Li, M.; Wang, D.; Jiao, Y.; Qi, X.; Wang, M.; Liu, Z.; Chen, C.; Wang, Y.; et al. A DMP-triggered in vivo maternal haploid induction system in the dicotyledonous Arabidopsis. Nat. Plants 2020, 6, 466-472. [CrossRef] [PubMed]

79. Ravi, M.; Chan, S.W.L. Haploid plants produced by centromere-mediated genome elimination. Nature 2010, 464, 615-618. [CrossRef] [PubMed]

80. Karimi-Ashtiyani, R. Centromere engineering as an emerging tool for haploid plant production: Advances and challenges. In Doubled Haploid Technology Vol. 3. Emerging Tools, Cucurbits, Trees, Other Species; Seguí-Simarro, J.M., Ed.; Methods in Molecular Biology; Springer Science + Business Media: New York, NY, USA, 2021; Volume 2289, pp. 3-22.

81. Kuppu, S.; Ron, M.; Marimuthu, M.P.A.; Li, G.; Huddleson, A.; Siddeek, M.H.; Terry, J.; Buchner, R.; Shabek, N.; Comai, L.; et al. A variety of changes, including CRISPR/Cas9-mediated deletions, in CENH3 lead to haploid induction on outcrossing. Plant Biotechnol. J. 2020. [CrossRef] [PubMed]

82. Kelliher, T.; Starr, D.; Wang, W.; McCuiston, J.; Zhong, H.; Nuccio, M.L.; Martin, B. Maternal haploids are preferentially induced by CENH3-tailswap transgenic complementation in maize. Front. Plant Sci. 2016, 7. [CrossRef]

83. Kelliher, T.; Starr, D.; Su, X.; Tang, G.; Chen, Z.; Carter, J.; Wittich, P.E.; Dong, S.; Green, J.; Burch, E.; et al. One-step genome editing of elite crop germplasm during haploid induction. Nat. Biotechnol. 2019, 37, 287-292. [CrossRef]

84. Lv, J.; Yu, K.; Wei, J.; Gui, H.; Liu, C.; Liang, D.; Wang, Y.; Zhou, H.; Carlin, R.; Rich, R.; et al. Generation of paternal haploids in wheat by genome editing of the centromeric histone CENH3. Nat. Biotechnol. 2020. [CrossRef]

85. Stajic, E.; Kielkowska, A.; Murovec, J.; Bohanec, B. Deep sequencing analysis of CRISPR/Cas9 induced mutations by two delivery methods in target model genes and the CENH3 region of red cabbage (Brassica oleracea var. capitata $\mathrm{f}$. rubra). Plant Cell Tissue Organ Cult. 2019, 139, 227-235. [CrossRef] 
86. Karimi-Ashtiyani, R.; Ishii, T.; Niessen, M.; Stein, N.; Heckmann, S.; Gurushidze, M.; Banaei-Moghaddam, A.M.; Fuchs, J.; Schubert, V.; Koch, K.; et al. Point mutation impairs centromeric CENH3 loading and induces haploid plants. Proc. Natl. Acad. Sci. USA 2015, 112, 11211-11216. [CrossRef]

87. Kalinowska, K.; Chamas, S.; Unkel, K.; Demidov, D.; Lermontova, I.; Dresselhaus, T.; Kumlehn, J.; Dunemann, F.; Houben, A. State-of-the-art and novel developments of in vivo haploid technologies. TAG Theor. Appl. Genet. 2019, 132, 593-605. [CrossRef]

88. Hirakawa, H.; Shirasawa, K.; Miyatake, K.; Nunome, T.; Negoro, S.; Ohyama, A.; Yamaguchi, H.; Sato, S.; Isobe, S.; Tabata, S.; et al. Draft genome sequence of eggplant (Solanum melongena L.): The representative solanum species indigenous to the old world. DNA Res. 2014, 21, 649-660. [CrossRef] [PubMed]

89. Barchi, L.; Pietrella, M.; Venturini, L.; Minio, A.; Toppino, L.; Acquadro, A.; Andolfo, G.; Aprea, G.; Avanzato, C.; Bassolino, L.; et al. A chromosome-anchored eggplant genome sequence reveals key events in Solanaceae evolution. Sci. Rep. 2019, 9, 11769. [CrossRef]

90. Saini, D.K.; Kaushik, P. Visiting eggplant from a biotechnological perspective: A review. Sci. Hortic. 2019, 253, 327-340. [CrossRef]

91. Alam, I.; Salimullah, M. Genetic engineering of eggplant (Solanum melongena L.): Progress, controversy and potential. Horticulturae 2021, 7, 78. [CrossRef]

92. Maioli, A.; Gianoglio, S.; Moglia, A.; Acquadro, A.; Valentino, D.; Milani, A.M.; Prohens, J.; Orzaez, D.; Granell, A.; Lanteri, S.; et al. Simultaneous CRISPR/Cas9 editing of three PPO genes reduces fruit flesh browning in Solanum melongena L. Front. Plant Sci. 2020, 11. [CrossRef] [PubMed] 